\title{
Negotiation in Strategy Making Teams: Group Support Systems and the Process of Cognitive Change
}

\author{
Fran Ackermann · Colin Eden
}

Published online: 18 October 2008

(C) Springer Science+Business Media B.V. 2008

\begin{abstract}
This paper reports on the use of a Group Support System (GSS) to explore at a micro level some of the processes manifested when a group is negotiating strategy-processes of social and psychological negotiation. It is based on data from a series of interventions with senior management teams of three operating companies comprising a multi-national organization, and with a joint meeting subsequently involving all of the previous participants. The meetings were concerned with negotiating a new strategy for the global organization. The research involved the analysis of detailed time series data logs that exist as a result of using a GSS that is a reflection of cognitive theory.
\end{abstract}

Keywords Negotiation · Group support systems · Strategy making

\section{Introduction}

The research reported in this paper seeks to understand how senior managersmembers of a top management team (TMT) — change their mind as they negotiate agreements in real strategy making episodes. Each member of the TMT is likely to come to a strategy meeting with a different perspective on what the major strategic issues facing the organization are. Indeed, the specific roles of each manager require that they bring different perspectives: for example, financial, marketing, production and supply, and human resources. As agreements are sought there is, at least, some hope that a degree of consensus might be reached-some commonality of understanding,

\footnotetext{
F. Ackermann $(\varangle) \cdot$ C. Eden

Strathclyde Business School, 40 George Street, Glasgow, Scotland, UK

e-mail: fran.ackermann@strath.ac.uk

C. Eden

e-mail: colin@gsb.strath.ac.uk
} 
rather than depending solely upon power plays or compromise. This research focuses on the manner in which a group support system both facilitates and records shifting cognition—cognitive/psychological negotiation—in real strategy making.

For a number of reasons Group Support Systems (GSS) have been used to support strategy making groups negotiate towards an agreed direction (de Vreede et al. 2003; de Vreede and de Bruijn 1999; Eden and Huxham 2001; van den Herik and de Vreede 2000). They provide anonymity (Jessup and Tansik 1991; Valacich et al. 1992), increased group productivity (Jessup and Valacich 1993), a greater potential for collaborative working (Agres et al. 2005; Briggs et al. 2003), and often the use of visual interactive modeling (Ackermann and Eden 2001).

In addition, a GSS may particularly facilitate psychological negotiation within groups, supporting groups in reaching agreements about the strategic direction. To develop the means of enabling the exploration of this negotiation capability, two existing arenas of negotiation research were employed to assist in the design and usage of the GSS. The first of these, international conciliation, guided by principles set out by Fisher and Ury (1982)_ “"getting to yes", were a powerful guide when designing the GSS used to negotiate strategy. The second concentrated on a structure for strategy (Eden and Ackermann 2001) that maps onto principles of cognitive psychology guided by personal construct theory (Kelly 1955)—-making sense in order to act-which was employed to facilitate cognitive negotiation.

To begin to understand the use of GSS's within these specific arenas of negotiation, the paper focuses upon a series of strategy making interventions within the context of a single multi-national corporation (based in the US and Europe). The first three meetings comprised senior management teams (of around 8-9 members) from each of the three operating companies. An identical design was used where the purpose of the meetings was to determine and deliver competitive positioning with respect to the exploitation of organizational distinctive competencies. Subsequently the three top management teams came together as a corporate executive team with an expectation of reaching agreements about important common strategies for the future. In this meeting a model, comprising the unfolding strategy models generated from the initial work woven together, formed the basis for negotiating a strategy for the corporation. The GSS was used throughout the interventions. The entire intervention spanned a single month period (ensuring that the material was fresh in all the participant's minds).

This use of a GSS allowed the researchers to not only facilitate a group strategy making effort but also monitor at a detailed level the GSS contributions of each and every participant over time. As such it provided the researchers with the means to explore the dynamics of cognition: how participants contribute to, and make sense of, their views and the views of others; and explore many aspects of how agreements were reached. It should be noted that this research focused on individual cognition as a basis for group negotiation, in contrast to that proposed by Sheetz et al. (1994) and Tegarden and Sheetz (2003) who focus on capturing group and organizational thinking.

Although for many years there has been an interest in studying the dynamics of cognition, researchers have argued that a focus on one individual at a time would mean that little would be discovered about the cognitive aspects of group working (Walsh 1995). Indeed, some feared that research would only be capable of offering insights 
on organizations 'one brain at a time' (Weick and Roberts 1993, p. 358). This research seeks to address these issues, at least to some degree, although, as with most research on cognition, the data (logging of contributions along with their timing) is very much a surrogate for cognition (Eden 1992). Thus, in progressing our understanding of managerial cognition it is important to both recognize this consideration but nevertheless aim to move the field forward. This research therefore attempts to follow changing 'cognition' ( a form of negotiation) throughout a series of strategy meetings.

As well as exploring changing cognition in strategy making the research also seeks to understand the role of a GSS in facilitating negotiation. Although there has been considerable research undertaken that confirms the efficacy of GSSs there is little, if any knowledge, of how groups, using such systems navigate the process of negotiating towards agreed outcomes. However, through being able to examine second by second the entries made by participants', insights into the process of negotiation can be elicited. This is of interest not just to those working in the area of group support but also to those interested in managerial and organizational cognition-specifically collective cognition.

Thus, this research sets out to explore the dynamics of cognition, concentrating upon the principles set out by Fisher and Ury, and the role of a GSS in facilitating negotiation. The research has important implications for both theory and practice. Specifically these implications are in relation to (i) "getting to yes" and the role of a GSS, (ii) managerial and organizational cognition, (iii) collective cognition. We draw these implications together with respect to their impact on the design of group support systems and knowledge management.

The content of this paper therefore reports upon aspects of cognition that were derived from the use of a Group Support System and causal mapping in the negotiation of strategy with a multinational company. The nature of the specific Group Support System and the form of causal mapping used in these interventions are elaborated below. The paper commences with a brief consideration of relevant aspects of literature pertaining to negotiation before discussing the research method adopted, the analysis and the implications and limitations. It concludes with a brief summary.

\section{Aspects of Negotiating Strategy}

\section{1 "Getting to Yes"}

In their book "Getting to Yes", Fisher and Ury (1982) set out very clear principles for successful negotiation. They argued that "four points define a straightforward method of negotiation that can be used under almost any circumstance.

- People: separate the people from the problem.

- Interests: focus on interests, not positions.

- Options: generate a variety of possibilities before deciding what to do.

- Criteria: insist that the result be based on some objective standard" (p. 11).

Separating the people from the problem also "means structuring the negotiating game in ways that separate the substantive problem from the relationship and protecting people's egos from getting involved in substantive discussions. ... The more quickly 
you can turn a stranger into someone you know, the easier a negotiation is likely to become" (p. 38). Another important aspect of Fisher and Ury's approach to negotiation is the premise that it is better to develop new options than fight over old options.

These principles derive from their interest in international conciliation, but, as they suggested above, might apply in almost any circumstance including strategy negotiation. Moreover, given these points, GSSs seem to be an obvious candidate for the application of these principles. This research seeks to explore these principles within the context of using a GSS for facilitating negotiation in strategy making teams.

\subsection{Cognition and Psychological Negotiation: Managerial and Organizational Cognition}

Given the above discussion, in this research cognitive and psychological negotiation are taken as one aspect of developing an understanding of negotiation of strategy in groups. The coherent body of psychology theory used to frame this research (the second arena) derives from that which guided the development of causal mapping used by the GSS. Personal Construct Theory (PCT) is founded upon an understanding of human activity being guided by the need of a person to make sense of a situation in order to act in it: "A person's processes are psychologically channelized by the ways in which he anticipates events" (Kelly 1991, p. 32). Thus, it is about problem construction and the act of management. PCT is mostly set out as a series of corollaries (Fransella and Bannister (1977, p. 5) provide a more extensive summary of the corollaries) and those that are appropriate for this study are as follows:

- Individuality: persons differ from each other in their construction of events. Therefore being able to capture these differences will provide a valuable starting point for the process of psychological negotiation as all views are attended to.

- Experience: person's construction system varies as he successfully construes the replications of events (including from gaining support in a group). Therefore the act of recalling and structuring contributions acts as a form of sense making and reflection furthering the process of negotiation.

- Sociality: to the extent that one person construes the construction processes of another; he may play a role in a social process involving the other person. Therefore enabling the map to allow other participants to view the ideas of one another without the need to immediately respond, and the facility to see differences between views triggering new opportunities, further negotiation is able to take place.

- Commonality: to the extent that one person employs a construction of experience which is similar to that employed by another; his psychological processes are similar to those of the other person.

It is these aspects of cognition that will be explored.

\subsection{Negotiating Collective Cognition}

If we talk of collective cognition what is it that we mean? Within the context of Personal Construct Theory we are concerned to understand the degree of sociability and 
the degree of commonality. Thus within the context of a top management team (TMT) discussing strategy we would expect the process of reaching agreements to show a shift from higher levels of individuality to an increasing degree of cognitive alignment. That is to say, observing an effective management team exploit the multiple perspectives brought to bear on a situation the management team faces, and arrive at an increasingly collective view that allows agreements to be reached and collective action to follow. For example, in deliberating about strategy each member of the team is likely to have a different perspective on the nature of an appropriate strategic future and a view on the best way of getting there, however through negotiated process they are able to move to a more common view.

Thus, a good strategy meeting might enable each member of the team to be able to elucidate their different perspectives, to listen carefully to the perspectives of others, to shift their own position, and to be able to reach an agreement that does not do too much violence to their position. If negotiation occurs then each construct system will be elaborated in response to the perspectives of others. The outcome of collective cognition is to expect a higher degree of coordinated action than would otherwise be the case. Another way of putting this is to expect that each participant to the strategymaking meeting is less surprised than they would otherwise be at the behavior and actions taken by their colleagues subsequent to the meeting. None of this is to imply that any management team should, or would, move to a position of complete collective consensus. Nevertheless at the other extreme, and in circumstances where the views held by each participant remain unaffected by the views of others, no negotiation, neither social nor psychological, will have taken place.

To summarize we were interested in monitoring this process of collective sharing, understanding, and negotiation. We were interested in the role that the Fisher and Ury principles, as expressed through the GSS, played in enabling cognitive and social negotiation.

\subsection{The Process, Technique and Technology for Strategy Negotiation}

As noted above, a group support system (GSS) incorporating causal mapping was used to support the strategy making process. This system has been used to support a wide range of organizations (public and private, large and small, national and international) in both strategy making and problem resolution (see, for example, Bryson 2004; Eden and Huxham 2001; Eden and Ackermann 2001; Mingers and Rosenhead 2004).

\subsubsection{Group Support System Processes}

The GSS used for the intervention provided either the facility for participants to directly contribute their views through a multi-user system where all participants can communicate with a public display showing the causal map they are jointly creating (Group Explorer) or via the facilitator who directly manages the causal mapping software (Decision Explorer) (Ackermann and Eden 2001). Group Explorer uses wireless networked computer consoles (see Bryson et al. 2004 for a detailed description) and provides participants with the ability to surface a range of views (action statements 
with causal relationships), explore how their views relate to the views of the rest of the group, and subsequently express preferences and undertake prioritization. All of these activities are able to be anonymous and allow for simultaneous contribution. It was used for about $70 \%$ of each meeting session.

For each of the three meetings involving the top management team of the operating company, each participant utilized a single console through which they could anonymously type statements (nodes on the causal map), place causal links, and in addition express preferences indicating preferred options, the preferential allocation of resources, or objections to proposed actions. A chauffeur console (which is separate from both the participant consoles and the computer driving the public screen) provided the facilitators with information on the rate each participant generated material, the extent of contribution from each participant with respect to a cluster of statements, and the authorship of individual statements or links and the authorship of preferences. The chauffeur information contributed to the management of the group processes. In addition the system logged over time every transaction-that is all the statements, causal links, and preferences entered by the participants. In this paper we use analyses of the logs from each of the meetings.

\subsubsection{Causal Mapping}

The causal mapping technique used in this strategy making process is informed by the principles of cognitive mapping that are based upon Personal Construct Theory (Goodwin and Wright 1998) and comprises a set of 'formalisms' (see Bryson et al. 2004 for a full description of the formalisms). The formalisms are not introduced to participants but rather learned 'naturally' as the maps are developed. The cognitive mapping technique enables a representation of the thinking of an individual to be created. It was developed as an improvement on the Repertory Grid technique (Fransella and Bannister 1977; Wright 2006) originally developed by Kelly_an approach inappropriate for exploring managerial cognition (Helmer 1983).

For Kelly, as noted earlier, psychological negotiation occurs through the conscious elaboration of a person's construct system. In this case the transitional object-a publicly viewable projected causal map - is the vehicle expected to encourage each participant to elaborate their construct system and so change their mind incrementally. The map changes to reflect new aspects of the conversation (both statements and links) among group members and negotiated agreements - thus is in transition. Through the use of this map, group members are less pressured to respond immediately, but rather can read the contributions in their own time and so contribute from a cognitive rather than physiological or solely emotional stance. The map or model is essentially a directed graph with statements being linked to one another through causal relationships. Meaning is transmitted through the context of statements (other statements linking in and out of the statement). These other statements comprise explanations and consequences, namely what affects the statement (explanations) and what might be expected to result from implementation of the action implied by the statement (consequences). Thus, in part, there is an attempt to represent, through the use of a causal map, collective cognition (the views of group members often amounting to several hundred statements and causal links). 
Causal mapping reflects the formalisms of cognitive mapping but is extended by imposing a structure of strategy maps (Cole 1958; Eden and Ackermann 2001) and encompasses the views of a number of participants (rather than an individual). A strategy map invites a 'Business Model' type of structure encompassing goals or negative outcomes, distinctive competences, competences, strategic issues, and problems or opportunities (Ackermann, Eden with Brown 2005). This structure is not imposed during the construction of a causal map but rather used to organize the contributions. The map is constructed through conversation between participants in a group process.

The maps developed in this research were all constructed in the presence of all participants and comprise content derived from only those participants (for further discussion and examples of the construction of maps in a group setting see Bryson et al. (2004) and Ackermann, Eden with Brown (2005)). However, statements and causal links comprising the maps emerge at different stages in the strategy-making meeting process-recognizing the dynamic nature of negotiation.

\section{Research Design}

It is important to reiterate that while cognition plays a role in psychological negotiation in these settings, this study cannot be regarded as a study of cognition per se-but rather the products of cognition which are woven together to form a transitional object that can support negotiation.

Nevertheless, as noted in the introduction, regardless of the difficulty in identifying and examining managerial cognition, if studies of managerial cognition are to make progress then it is important to at least study managers in real situations that they see to be important. Gaining access to such situations is always problematic and often leads, as in this case, to the use of action research as the most appropriate research methodology (Eden and Huxham 1996). In this particular instance the authors were privileged to gain data from three separate management teams within the same organization, each involved in the same task, and all involved in a final meeting. Thus the data from this intervention set can yield important insights into the process of negotiation within real strategy making teams.

The general basis for developing and testing approaches to strategy making (guided by a system of theories) has been to work in a "Research Oriented Action Research" format (Eden and Huxham 2006) specifically following the cyclical research process proposed originally by Susman and Evered (1978).

In addition to the interventions, an independent researcher (who was not involved in the meetings) subsequently analyzed the computer logs from each of the meetings. The researcher was given the 'raw data' in terms of the strategy models and computer logs. Various statistical analyses such as similarity matrices (Pearson correlation coefficients) were used to explore the data as was exploring the patterns of statement and link contribution over time (in the form of a 'movie'). In order to ensure an appropriate contextual interpretation of these data two other sources of research notes were used (Evered and Louis 1981). Firstly, as there were two facilitators for each meeting, detailed notes from the interventions that were written up based upon observations made during the meetings were used. Secondly, there were two senior managers of 
the organization who worked in partnership with the facilitators and their comments contributed to the interpretation of the analyses.

\section{Analysis}

\subsection{Alignment and Differentiation in Shared Meanings}

Alignment does not mean that the detailed construal of the problem(s) is identical or even similar, but rather that there is some agreement about what to see and what not to see. The effective team will depend upon each team member offering different ways of understanding even though they may use the same problem label. Thus, alignment is important for understanding the likelihood of coordination and cooperation. In developing a group causal map the degree of alignment (or what Klimoski and Mohammed 1994 called homogeneity of cognition) at any point in time could be viewed as the extent to which: (i) participants presume alignment and so immediately seek to develop their own thinking alongside that of others, rather than developing their own views; (ii) participants link their own views with the views of others rather than continually elaborating their own views; (iii) participants develop clusters of material (views) that are relatively isolated from the views of others.

Examination of the data $\operatorname{logs}$ showed that contributions consistently followed a bi-modal pattern. Initially participants entered their own personal views without regard for the views of others-revealing considerable amounts of apparent differentiation. However, once each participant had exhausted their most immediate contributions they moved their focus to the GSS public screen and began to review the material generated by others (evidenced through a pause in contributions of up to 10 mins). This scrutiny triggered further views; however these contributions were often extensions or further considerations of points already made by others, giving rise to some level of alignment.

This bi-modal process continued during the linking stages as participants shifted their emphasis from personal connectivity to linking their own views to the views of others. However, this was not the case for all participants: some participants focused their attention on only linking their own material. Others started by just linking theirs and then moved on to linking between themselves and others. Contribution rates also varied with some participants contributing a lot of links very quickly and then 'sitting back' while others worked at a slower pace but for longer. There was some concern that linking might be heaviest where the initial linking of statements took place as this would naturally draw the eye to that place on the screen, however, analysis of the material showed this not to be the case. The patterns of behavior, where some participants linked single pairs of statements, others linked complete chains or statements, and others focused on a particular statement and linked a large number of statements in or out of the focal statement replicated the finding reported by Shaw (2003).

In both instances (statement and link generation) the different contribution phases suggested that participants shift the emphasis of their thinking from dealing with those issues immediately of concern (differentiation) to 'listening' and building on the contributions of others 
One of the analyses carried out on the data logs was the creation of a 'movie' displaying over time the contribution of links. Statements were categorized by proponent and colored accordingly. Likewise links were attributed the proponent's color. Taking 5-s intervals, the movie was then created showing when and where links were generated. For example, if proponent A (denoted in red) linked one of his/hers to another of his/hers and subsequently to another of hers/his this would show up as a set of red links. Figure 1 shows 3 'pictures' from the movie, representing different stages in the process but in black and white rather than color (different fonts are used to show different participants).

Each number tag (in Fig. 1) represents a statement from each of 8 different participant's (labelled participant A-H) with different styles (fonts and borders) differentiating each of the participants. The number tags are simply those that the software uses in order to be able to manipulate each statement-during the meetings the participants entered their statements in the GSS which allocated the number tag in the order the statements arise. Similarly, the causal links are differentiated according to which participant made the link (through a variety of link styles). This was purely for the benefit of the analysis, in a group meeting links and statements appear in the same form-there is no explicit differentiation of participants. Each of the 'pictures' shows a particular point in time - a progression-which replicates the actual layout seen by participants at that time. The diagrams are intended to reveal the different patterns noted in the paper: for example, participants linking their own statements, linking their statements to those of other participants, and participants linking statements that were not contributed by them. For example, in Fig. 1b, participant D links a statement contributed by participant A to a statement contributed by participant E.

Thus the different patterns for contributing that emerged from this analysis of the data were:

- some participants generated only a few statements, and when linking material concentrated in the main on their own material sometimes simply putting in single links (rather than a complete chain of argumentation).

- some added many statements but very few links - as such they had an impact on the overall structure but did little to pull it together, appearing to be content to let others create meaning from the contributions.

- some participants focused on a particular area or issue-generating lots of contributions (both statements and links) resulting in a tightly woven area of the overall map.

As such the dynamic examination revealed a number of interesting insights that have already been touched on: the tendency for some to focus only on their own material compared with others who not only wove their views into the whole but in some cases focused almost exclusively on linking the views of other proponents together. These participants in particular would move around the map, putting links in, and addressing a range of different areas. As a result of this linking some of the contributions were extensively developed, whilst others became relatively peripheral suggesting some implicit prioritization. Moreover, these different patterns of contribution may suggest particular modes of 'making' sense and styles of negotiation. However it must also be borne in mind that where participants link other's material together this could be an attempt to make sense of the material and/or impose a structure that is congruent with 


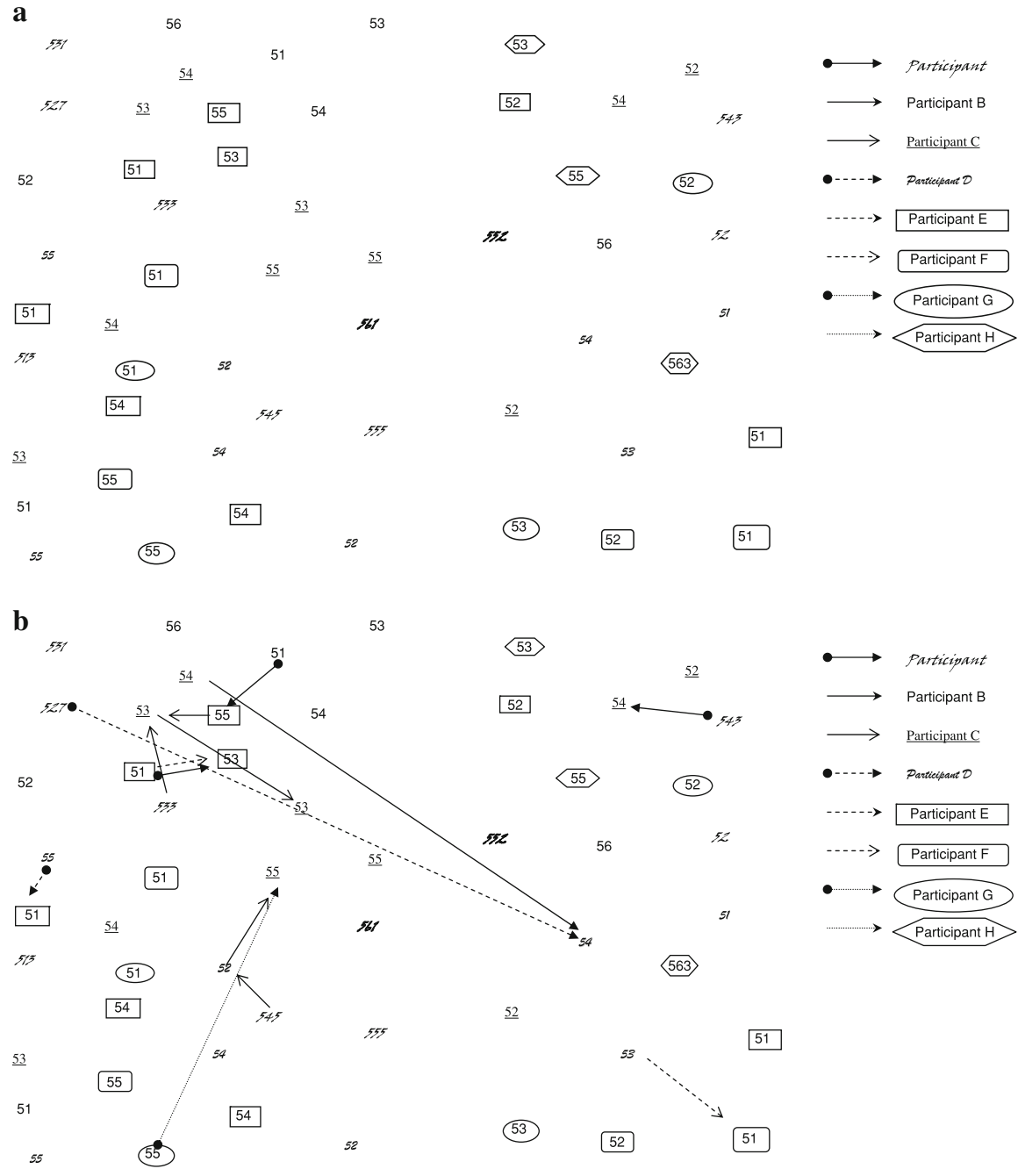

Fig. 1 a A part of the 'movie' of a developing causal map (fonts and icons represent each participant, and the participants have been anonymized) b A part of the 'movie' of a developing causal map (fonts and icons represent each participant, and the participants have been anonymized) c A part of the 'movie' of a developing causal map (fonts and icons represent each participant, and the participants have been anonymized)

the participant's own material — an act of political persuasion not cognitive alignment. Another consideration arises from considering the composition of groups where participants who make links across the material may be essential to a group negotiation.

\subsection{Reaching Agreements}

Whether it is true or not, statements such as "we now have pretty much same point of view and so can move on" occur in meetings involved in the resolution of strategic 


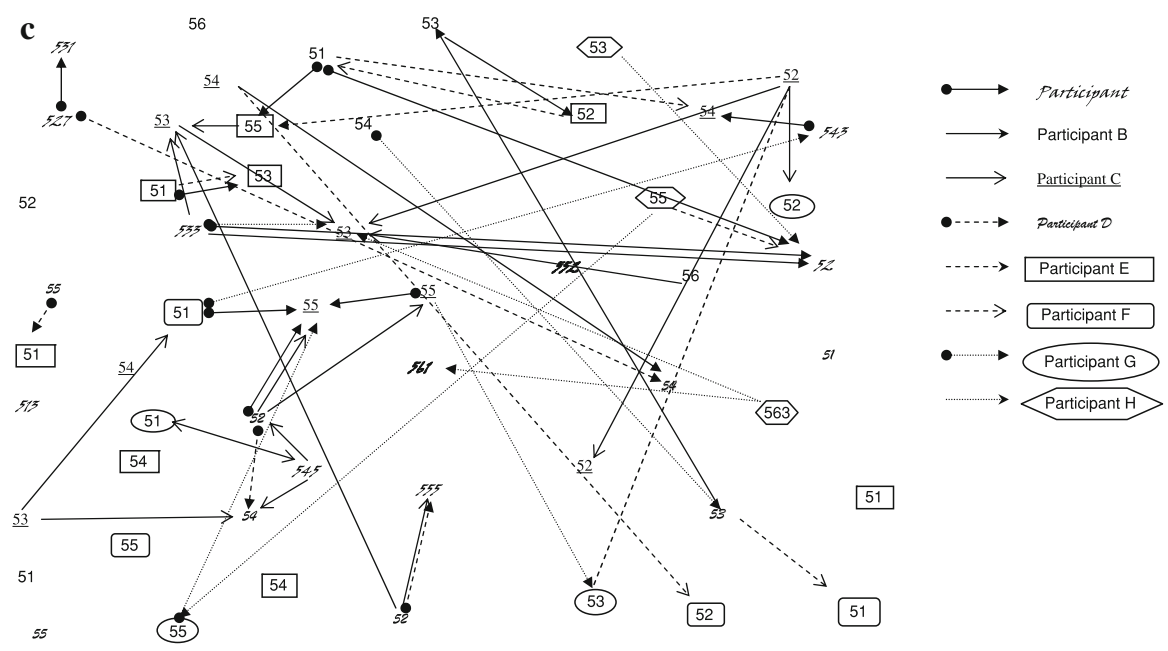

Fig. 1 Continued

issues. This typically means "we have moved to a common enough point of view for agreement to be possible". Needless to say, when these statements are made they indicate sometimes an attempt to impose a false consensus in order to avoid further debate.

An important measure for understanding negotiation is the extent to which participants are able to develop consensual agreements about action. This was assessed by comparing preferences assigned by individuals during the evaluation of a series of competing options-determining those options that would be actioned. These evaluations involved anonymously rating the options against an anchored scale-allowing the capture of preference. Pearson correlation coefficients were subsequently calculated between vectors of scores for each pair of individuals; these coefficients were entered in a similarity matrix (see Fig. 2 for an example of a matrix) and coded to show the strength of agreement or disagreement. The analysis identified groups of people whose views were closely aligned, and thus options where there was strong agreement and options where there was little agreement.

The numbers can be interpreted as follows:

- A value of 1 between 2 people means it is possible to work out one person's views if the other is known. That is, there is a linear relationship between their scores, but they are not necessarily the same. An example might be that one of the participants has scores of 50, 70 and 90, and the other has 50,60 and 70, so an increment of 20 for the 1 st person is consistent with an increment of 10 for the 2 nd.

- A value close to one suggests that there is a strong likelihood that the right answer might be gained for one participant's views if other participant's view is already known but this is not guaranteed.

- A value of 0 means that there is absolutely no relationship. It is impossible to work out one participant's scores from the others.

- A negative value means that participants have opposing views. The more negative the value, the more contrary their views. The lowest possible score is -1 . 
Proximity Matrix

Correlation between Vectors of

Values

\begin{tabular}{llllllllllll} 
& $2: \mathrm{A}$ & $3: \mathrm{Aa}$ & $4:$ Bre & $5:$ Bry & $6: \mathrm{Da}$ & $7: \mathrm{De}$ & $8: \mathrm{M}$ & $9: \mathrm{P} \& \mathrm{D}$ & $10: \mathrm{R}$ \\
\hline 2:A & 1.000 & 0.605 & 0.662 & 0.767 & 0.874 & 0.962 & 0.892 & 0.280 & 0.875 \\
\hline 3:Aa & 0.605 & 1.000 & 0.339 & 0.519 & 0.473 & 0.663 & 0.612 & 0.599 & 0.632 \\
4:Bre & 0.662 & 0.339 & 1.000 & 0.818 & 0.720 & 0.750 & 0.884 & 0.462 & 0.785 \\
5:Bry & 0.767 & 0.519 & 0.818 & 1.000 & 0.847 & 0.862 & 0.935 & 0.474 & 0.697 \\
6:Da & 0.874 & 0.473 & 0.720 & 0.847 & 1.000 & 0.873 & 0.898 & 0.341 & 0.865 \\
7:De & 0.962 & 0.663 & 0.750 & 0.862 & 0.873 & 1.000 & 0.947 & 0.314 & 0.879 \\
8:M & 0.892 & 0.612 & 0.884 & 0.935 & 0.898 & 0.947 & 1.000 & 0.522 & 0.896 \\
\hline 9:P\&D & 0.280 & 0.599 & 0.462 & 0.474 & 0.341 & 0.314 & 0.522 & 1.000 & 0.463 \\
\hline 10:R & 0.875 & 0.632 & 0.785 & 0.697 & 0.865 & 0.879 & 0.896 & 0.463 & 1.000 \\
\hline
\end{tabular}

This is a similarity matrix

\begin{tabular}{|llllll}
\hline & \multicolumn{1}{c}{1} & & & agree totally \\
\hline over & 0.9 & & & high positive \\
between & 0.7 & and & 0.9 & medium positive \\
\hline between & 0.5 & and & 0.7 & low positive \\
\hline between & -0.3 & and & -0.1 & low negative \\
\hline between & -0.5 & and & -0.3 & medium negative \\
\hline under & -0.5 & & & high negative \\
& & & & & may be some \\
agreement
\end{tabular}

Fig. 2 A sample of a similarity matrix

It is recognised that there are different ways of constructing a similarity matrix and various alternatives were undertaken however this analysis was the most appropriate for measuring the similarity of views. However it must be noted that the analysis assumes participants allocate their preferences consistently using an interval scale, so results should be treated with caution. 
An examination of this data again showed different patterns of behavior. It was no surprise that initially participants gave significantly higher scores to contributions they had entered themselves or were directly linked to ones they had entered. However, as the causal maps were developed (wording elaborated, new statements contributed to add meaning, and new links added), options were increasingly judged on their 'merit' rather than with respect to the original proponent. The alignment of groups with similar views could not be predicted from the disposition of the originator of statements and links. Increasingly a collective view seemed to emerge where at least two-thirds of the map appeared to belong to each participant (due to each being involved to some extent in the surfacing and amending of both statements and links), although different parts of the map.

\subsection{Group Plenary Meeting}

The group plenary meeting took place with the participants who had been involved with the operating company meetings (there were two omissions due to holidays, illness etc.). The meeting took place within one month of the other meetings. Unlike the operating company meetings, however, in this meeting participants had to share a laptop computer with two others, rather than have a dedicated machine. This to some extent was deliberate as it would ensure that more direct social interaction could take place-participants could seek to agree what they were going to contribute. However this was not prescribed and each participant could contribute their own views and share the preferencing resources. Each trio consisted of one person from each operating company.

Before the meeting three sets of causal maps existed, one for each operating company-these maps demonstrated significantly different views about strategy development. There were some similar statements in each map, but these statements did not usually carry the same meaning. A single causal map was generated where similar statements were merged (Eden and Ackermann 1998) — so bringing together their different meanings through the combining of all links into and out-of statements-or linked together where there was the possibility of different meaning. A matter of significance for negotiating agreements was the extent to which these different meanings could come together to create a collective meaning. In some cases there were different statements (words) that nevertheless suggested similar meanings. Figure 3 below shows how similar labels may have a different meaning and different labels might have a similar meaning.

During the meeting there was a considerable amount of development work on existing statements with participants from all of the operating companies contributing both refinements and new material. Meanings were changed, and in most cases refined. All trios made contributions to all clusters. As such the material that was selected for prioritization was in essence newly created material (rather than arguing over old options).

When examining the preferencing data, it appeared, based both on the data from the $\log$ and observations made during the meeting, that console groups reached agreements where to allocate their preferences rather than simply dividing up their preferences 
Fig. 3 Different labels, same meaning. Same label, different meaning (from Eden et al. 1983)
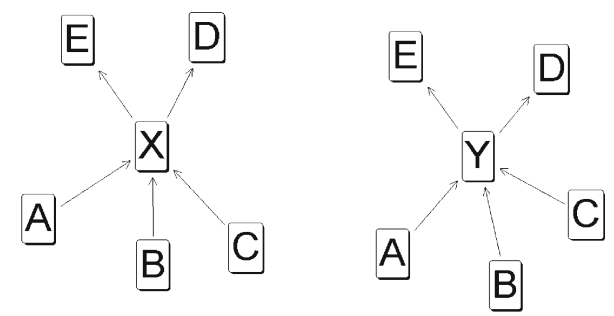

\section{Different label, same meaning}
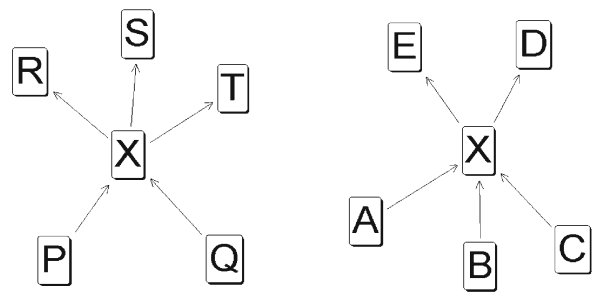

\section{Same label, different meaning}

into three equal parts. In addition, console groups did not focus on contributions they had made as a group during the plenary contributions or, more often than randomly, on those made by a member of the group during the operating company meeting.

\section{Theory and Practice}

In this section we return to the literature that framed the research, and we comment on its significance for negotiating strategy in the light of the research. Thus, we revisit to the specific arenas of negotiation, managerial and organizational cognition, and collective cognition.

\subsection{Negotiating Strategy}

\subsection{1 "Getting to Yes" and the Role of a GSS}

It is in applying the principles of procedural justice (Kim and Mauborgne 1991, 1995, 1998, 2001) and paying attention to the risks of group-think (Janis 1972; Normann 1985 ) that led to the use of a Group Support System. The GSS not only provided participants with the facility to be anonymous, but also enabled a high degree of equivocality necessary for facilitating negotiation by, (a) enabling views to be changed without 
penalty, (b) providing time to assimilate differences, and (c) supporting a greater understanding of the material to avoid misunderstanding and conflict. In addition the group support system allowed the fullest contribution of all the participants in influencing the discussion and thinking of the group (through anonymity, simultaneous input etc.) and along with the use of causal mapping moreover enabled the development and use of a 'transitional object' (Burt 2000; Winnicott 1953) to facilitate the negotiation-particularly through participants linking together the contributions of each participant.

As we note above and again below, many of the behaviors of participants are likely to be political in nature. As Fisher and Ury (1982) argue, "with many long-term clients, business partners, family members, fellow professionals, government officials, or foreign nations, the ongoing relationship is far more important than the outcome of any particular negotiation.” (p. 20). The GSS anonymity facility protects ongoing relationships and facilitates the retention of a negotiated social order (see Eden and Ackermann 1998, p. 49) and so allows more chance for sharing of cognition about substantive strategy issues. Most participants commented that the GSS separated the people from the problem. "Face-saving reflects a person's need to reconcile the stand he takes in a negotiation or an agreement with his principles and with his past words and deeds." (Fisher and Ury 1982, p. 29).

"It is true that a better understanding of [others] thinking may lead you to revise your own views about the merits of the situation. But that is not a cost of understanding their point of view it is a benefit." (Fisher and Ury 1982, p. 25: italics in original). This assertion was apparently exemplified throughout the analyses. The two stage process for each participant of declaring their own view and subsequently 'understanding' the views of others, and demonstrating this understanding by causally linking their views to others facilitated construct elaboration and so revision to their own views. This research suggests that processes that involve a transitional object that changes through the direct influence of a participant acts as a productive basis for sharing views and allows a better understanding of alternative views. From the point of view of deriving agreements with a high degree of ownership the creation of a representation of owned, collective 'cognition' agreements seems helpful. Similarly agreements that are commitments to outcomes that have been created by the collectivity (as in the case of the plenary session) are recalled by participants as belonging to them. To some extent this reflects the Fisher and Ury (1982) view that "If they are not involved in the process, they are hardly likely to approve the product" (p. 27) as well as Kelly's commonality corollary.

Designing incremental construct system elaboration (Kelly would argue this is the natural process of shifting cognition) through the use of a transitional object that reflects not just statements, but statements and their links, facilitates the creation of a collective view and so negotiation. "Nothing is so harmful to inventing as a critical sense or waiting to pounce on the drawbacks of any new idea. Judgment hinders imagination" and "if the first impediment to creative thinking is premature criticism, the second is premature closure." (Fisher and Ury 1982, pp. 60-61). The analyses suggest that it is the linking process that is the powerful way of sharing thinking and developing 'collective cognition'. The process of linking is, in many ways, the equivalent of "rather than ask about their positions ... ask about their interests" (p. 119)—-the out-arrows illustrate interests because they directly, or indirectly, relate to goals/values/purposes. 


\subsubsection{Managerial and Organizational Cognition}

As stated at the beginning of this paper, the focus of this research has been on exploring developing collective cognition. However, although managerial and organizational cognition has been a focus for much of this research, the significance of theories of power and politics in organizations, and emotion, is also overwhelming. Many of the acts undertaken by participants in the groups studied here can be interpreted as political acts even though they have collective cognition consequences. Creating change in organizations will always produce a political dynamic, and so the success of effective strategy making meetings can almost be measured by the extent of the political dynamic generated. There have been demands for some time for a managerial and organizational cognition perspective to take a greater account of emotion (most recently by Johnson 2009), and undoubtedly the emotional dimension to strategy meetings has been evident in the meetings studied here.

The notion of collective cognition is undoubtedly important in understanding the nature of reaching agreement in groups. Although this study imposed a very particular group process, it nevertheless enabled the collection of data in real time, rather than being based upon personal accounts of meetings. In addition, the researchers were integrally involved in the group processes and so could act as observers as well as facilitators (both an advantage and disadvantage-as noted above). Being party to informal and formal conversations outside of the group meeting, but about the group meeting, was possible, even though the conversations were influenced by the facilitators' presence. For this type of research an increase in the richness of the data set can only be a good thing as long as a data is treated carefully by the researchers.

Researchers interested in the nature of managerial and organizational cognition have for some years been making a plea for studies to go beyond a single time slice collection of cognition, and to study the dynamics of cognition. In this study particular attention has been given to changes in cognition, both with an interest in changes at the individual level and at the collective level.

However, to return to the particular aspects of personal construct theory that were regarded as of interest to this study, the following support is presented:

- Individuality: persons differ from each other in their construction of events.

We have seen that the most significant aspects of individuality lie in differences in meaning derived from causality_although similar statements might be made it was only possible to understand individuality through an analysis of links: what consequences followed from a statement (imagining acting in the world) and what reasons were given for outcomes occurring. Without allowing participants to elaborate meaning in this way there are likely to be false assumptions about cognitive alignment, and so false assumptions about agreements and their consequences.

- Experience: a person's construction system varies as he successfully construes the replications of events (including gaining support in a group). Therefore the act of recalling and structuring contributions acts as a form of sense making and reflection furthering the process of negotiation. 
In the plenary meeting there was evidence of reconstruing as the experiences of the operating company meetings had influenced views of all. Definitions of situations had changed and become more in line with a collective definition.

- Sociality: to the extent that one person construes the construction processes of another; he may play a role in a social process involving the other person.

This research was unable to track the role of sociality, except to suggest that the anticipation of alternative constructions of reality enabled links between different perspectives to occur-whether this enabled one person to "play a role in a social process" was difficult to observe. The use of a GSS discourages some aspects of social process in order to facilitate 'listening'.

- Commonality: to the extent that one person employs a construction of experience which is similar to that employed by another; his psychological processes are similar to those of the other person.

This research has shown that strategy making groups are unlikely to reach agreements unless there is a degree of similarity of psychological processes (that is to be expected within an organization). The lack of commonality was most acutely noticed across the operating companies - each of which was operating in different national cultures and within different market segments. To try to alleviate this the plenary meeting was complicated, deliberately, by creating sub-groups made up of someone from each operating company.

\subsubsection{Collective Cognition-How Would We Know It?}

Klimoski and Mohammed (1994) refer to 'team mental models', and undoubtedly the models (maps) developed in the plenary session could be regarded as a team mental model or a representation of group thinking (Sheetz et al. 1994; Tegarden and Sheetz 2003). The creation of the team mental model, in the instance of the plenary session, was seen as likely to have been influenced substantially by (i) the declaration of different perspectives at the beginning of the meeting with some tentative linking to show different meanings of common statements, and (ii) the enforced structure provided by the requirement to work in trios representing each operating company. Nevertheless, discussions with participants after the event suggested that they became increasingly uncertain about which contribution derived from which operating company or which person, and saw the group mental map as belonging increasingly to the group.

As a result of this research, what might we suggest would be a measure of the extent of collective cognition, or a group mental map? In this research participants were asked to enter statements and links between statements (their own or those of others), and to express preferences about where the strategic focus of the organization should lie. Analysis of the data from these interventions suggests that three sensible metrics for establishing the extent of collective cognition would be:

- increasingly expressing more links between statements of others;

- increasingly less dominance of linked statements and arrows attributed to a single person;

- increasingly less preference for their own contributions. 


\section{Implications for the Design of Group Support Systems and Knowledge Management}

As with normal group processes the behavior of each participant varies significantly within each meeting. One observation made from analyzing the $\log$ is that the introduction of the GSS did not result in an equality of contribution-contrary to propositions made in the GSS literature (Dennis and Gallupe 1993; Dennis et al. 1988). However, this has to be considered against how the participants would behave in a normal meeting and whether the contributions are more equal than a normal or typical meeting - and that data was not possible to collect precisely. Nevertheless, on the basis of our interactions with participants outside the meeting we feel reasonably confident in making some tentative statements about the comparison between behavior in the GSS and that experienced in normal meetings. For example, whilst it might be expected that the computer consoles significantly shifted the level of relative dominance regarding participants' contribution this does not seem to be the case.

Whereas anonymity encouraged each statement to be treated with respect to its content rather than with respect to the proponent, individual behavior did seem to match personality. What appears to be the case in the GSS meetings is that those participants who typically seek to draw together the contributions of others continued to do so by linking the statements of others together. Similarly those who contribute to normal meetings through the use of single statements continued to do so. Finally, those who expected to make a more lengthy statement based upon the development of an argument continued to do so. It is perhaps surprising that the introduction of technology did not seem to alter this form of behavior in the meetings; particularly as previous experience suggested the use of computer technology did transfer power to those who are computer literate especially during the early stages of our use of the system (15 years ago). However one change that did become obvious was that the GSS appeared to significantly reduce the power of those used to dominating discussion through power of rhetoric and charisma.

The evidence of patterns of contribution demonstrating bi-modality confirms our expectations of each participant wishing to express their own point of view before 'listening' to other members of the group by reading their contributions, and subsequently piggy-backing on those contributions. This observation supports recommendations made by Shaw (2003) for using blind gathering.

\section{Limitations of the Reliability of Data and Analyses}

There are a number of limitations that must be taken into account. These limitations comprise two topics, the first focuses around the actual intervention, the second around the nature of the computer based GSS. Concentrating on the intervention topic, a number of considerations need to be taken into account when viewing the results. The first limitation is that the group is deliberately being asked to do something different from their typical practice and this request may have an affect on what unfolds. However, reflecting on the meetings with the two organizational sponsors and other participants in the meeting it was clear that strategy making in that organization in general was an 
unusual activity and so any strategy making process would have led to new behaviors. And, as is always the case when working with real organizational groups, there is no ability to have a control group against which to compare behaviors.

Furthermore, this research was specifically concerned with seeking to understand more about the behavior of real senior management teams rather than of student groups where the group has no history of working together and no future accountability for agreements. In doing so, the research becomes messy-strict protocols for 'interviewing' participants are difficult to adhere to (Norburn 1989; Pettigrew 1992). Action research of this sort can expect to make a contribution to knowledge, where the aim is "to contribute both to the practical concerns of people in an immediate problematic situation and to the goals of social science by joint collaboration within a mutually acceptable ethical framework" (Rapoport 1970, p. 499 our emphasis).

A final limitation regarding the intervention and its analysis is that the facilitators were themselves were a part of the research team thus raising questions regarding the data and its interpretation, although using an independent analyst to some extent alleviated this.

Limitations regarding the computer system focus mainly on the fact that this was the first time that the logging system had been used for this research purpose (the GSS had been used extensively) and so no analysis on the data had been previously undertaken. As a result of analyzing the logs, it became clear that the data logging process should be enhanced by additional facilities, for example, inclusion of on line statistics (both for links and preferences). Also as the facilitators made changes to the location of statements on the map (in order to try to 'tidy' up the representation on the public screen in order manage the complexity) and, when requested by participants edited the contents, the system was not able to log these changes as being facilitator driven. As a result the maps provided to the researcher were not the evolving maps seen by the group.

\section{Summary}

This research has attempted to move forward our understanding of the dynamics of cognition in real organizational settings. In some respects it is imperfect because it has been unable to differentiate clearly between (i) expressing views on the substantive issues facing the organization from (ii) thinking about persuading others in a group setting. There was no attempt, or facility, to capture this 'different' type of thinking. Also there has been an assumption that the representation of cognition and agreements derived from it are agreements that will be undertaken. However, these issues have also arisen in previous studies of managerial cognition. Furthermore, the most notable studies of cognitive alignment have been based on single point in time data derived from interviews (Hodgkinson and Johnson 1995; Johnson et al. 1998; Porac et al. 1989). In this case the 'interviews' have been dynamic and the data taken from a real team deciding about something they declared as crucial to their own and their organization's future. Thus, we have sought to move the field forward rather than await the perfect methodology, the perfect research situation, and the fullest appreciation of what is going on in complex organizations. In particular, the use of the 'movies' showing 
the development of collective maps has proved to be methodologically interesting and deserves further use. These movies gave clear indications of different behaviors but they are difficult to show in an article or to formally analyze.

In addition, it may appear that many of the observations from the data sound obvious, and so possibly trivial. To state that managers focus on expressing their own point of view first is seemingly obvious, but what is not so obvious is the alternative processes of developing collective cognition. Indeed, anecdotal evidence from participants suggests that their behaviors as exemplified in these data match their behaviors in other social settings: those who seek to link their views with others did so, those who developed in detail their own views generally do so, etc. These different behaviors need exploring further in relation to their role in developing a collective view and reaching agreements.

Finally we feel that further research will be required to fully explore the implications of this research in terms of balancing alignment with differentiation. We have attached great importance to the process of developing alignment or a collective cognition, and yet we also need to focus on what it is that also retains creativity through differentiation (Simons et al. 1999). Differentiation is like entropy-a "measure of the disbalance of energy in the system" "a system gaining in entropy is also losing information" (Beer 1966, pp. 346-347).

\section{References}

Ackermann F, Eden C (2001) Contrasting single user and networked group decision support systems for strategy making. Group Decis Negot 10:47-66. doi:10.1023/A:1008708912048

Ackermann F, Eden C with Brown I (2005) The practice of making strategy. Sage, London

Agres A, de Vreede GJ, Briggs RO (2005) A tale of two cities-case studies on GSS transition in two organizations. Group Decis Negot 14:267-284. doi:10.1007/s10726-005-0315-6

Beer S (1966) Decision and control. Wiley, London

Briggs RO, de Vreede GJ, Nunamaker JF Jr (2003) Collaboration engineering with ThinkLets to pursue sustained success with group support systems. J Manage Inf Syst 19:31-63

Bryson JM (2004) Strategic planning for public and nonprofit organizations. 3. Jossey-Bass, San Francisco

Bryson J, Ackermann F, Eden C, Finn C (2004) Visible thinking: unlocking causal mapping for practical business results. Wiley, Chichester

Burt G (2000) Managerial recipes as transitional objects. PhD Thesis, University of Strathclyde

Cole RR (1958) Increasing utilisation of the cost-quantity relationship in manufacturing. J Ind Eng 9 (MayJune): $173-177$

de Vreede GJ, de Bruijn H (1999) Exploring the boundaries of successful GSS application: supporting inter-organizational policy networks. Database 30:111-113. doi:10.1145/344241.344248

de Vreede GJ, Davison R, Briggs RO (2003) How a silver bullet may lose its shine-learning from failure with group support systems. Commun ACM 46:96-101. doi:10.1145/859670.859676

Dennis A, Gallupe RB (1993) A history of group support systems empirical research: lessons learnt and future directions. In: Jessup L, Valacich J (eds) Group support systems—new perspectives. Macmillan, New York

Dennis A, George J, Jessup L, Nunamaker J, Vogel D (1988) Information technology to support electronic meetings. MIS Q 12:591-624. doi:10.2307/249135

Eden C (1992) On the nature of cognitive maps. J Manage Stud 29:261-265. doi:10.1111/j.1467-6486. 1992.tb00690.x

Eden C, Ackermann F (1998) Making strategy: the journey of strategic management. Sage, London

Eden C, Ackermann F (2001) A mapping framework for strategy making. In: Huff A, Jenkins M (eds) Mapping strategy. Wiley, London 
Eden C, Huxham C (1996) Action research for the study of organizations. In: Clegg S, Hardy C, Nord W (eds) Handbook of organization studies. Sage, Beverly Hills

Eden C, Huxham C (2001) The negotiation of purpose in multi-organizational collaborative groups. J Manage Stud 38:351-369. doi:10.1111/1467-6486.00241

Eden C, Huxham C (2006) Researching organizations using action research. In: Nord W (ed) Handbook of organization studies. Sage, Beverly Hills

Eden C, Jones S, Sims D (1983) Messing about in problems. Pergamon, Oxford

Evered R, Louis MR (1981) Alternative perspectives in the organizational sciences: inquiry from the inside and inquiry from the outside. Acad Manage Rev 6:385-386. doi:10.2307/257374

Fisher R, Ury W (1982) Getting to yes. Hutchinson, London

Fransella F, Bannister D (1977) A manual for repertory grid technique. Academic Press, London

Goodwin P, Wright G (1998) Decision analysis for management judgment. Wiley, Chichester

Helmer O (1983) Looking forward: a guide to futures research. Sage, London

Hodgkinson G, Johnson G (1995) Exploring the mental models of competitive strategists: the case for a processual approach. J Manage Stud 31:525-551. doi:10.1111/j.1467-6486.1994.tb00629.x

Janis IL (1972) Victims of group think. Houghton Mifflin, Boston

Jessup LM, Tansik DA (1991) Decision making in an automated environment: the effects of anonymity and proximity with a group decision support system. Decis Sci 22:266-279. doi:10.1111/j.1540-5915. 1991.tb00346.x

Jessup L, Valacich J (1993) Group support systems: new perspectives. Macmillan, New York

Johnson P (2009) Swapping collective cognition for collectivity in the strategic management literature. International studies in management and organization (forthcoming)

Johnson P, Daniels K, Asch R (1998) Mental models of competition. In: Eden C, Spender JC (eds) Managerial and organizational cognition. Sage, London

Kelly GA (1955) The psychology of personal constructs. Norton, New York

Kelly G (1991) The psychology of personal constructs volume 1: a theory of personality. Routledge, New York

Kim WC, Mauborgne RA (1991) Implementing global strategies: the role of procedural justice. Strateg Manage J 12:125-143. doi:10.1002/smj.4250120910

Kim WC, Mauborgne RA (1995) A procedural justice model of strategic decision making. Organ Sci 6: 44-61

Kim WC, Mauborgne RA (1998) Procedural justice, strategic decision making, and the knowledge economy. Strateg Manage J 19(4):323-338

Kim WC, Mauborgne RA (2001) How to earn commitment. Financial Times, October 22, p 8

Klimoski R, Mohammed S (1994) Team mental model: construct or metaphor. J Manage 20:403-437. doi:10.1016/0149-2063(94)90021-3

Mingers J, Rosenhead J (2004) Problem structuring methods in action. Eur J Oper Res 152:530-554. doi:10. 1016/S0377-2217(03)00056-0

Norburn D (1989) The chief executive: a breed apart. Strateg Manage J 10:1-15. doi:10.1002/smj. 4250100102

Normann R (1985) Developing capabilities for organizational learning. In: Pennings JM (ed) Organizational strategy and change, Jossey-Bass, San Fransico, CA

Pettigrew AM (1992) On studying managerial elites. Strateg Manage J 13:163-182

Porac J, Thomas H, Baden Fuller C (1989) Competitive groups as cognitive communities: the case of the scottish knitwear manufacturers. J Manage Stud 26(4):397-416

Rapoport RN (1970) Three dilemmas of action research. Hum Relat 23:499-513

Shaw D (2003) Evaluating electronic workshops through analysing the brainstormed ideas. J Oper Res Soc 54:692-705. doi:10.1057/palgrave.jors.2601568

Sheetz SD, Tegarden DP, Zigurs I, Kozar KA (1994) A group support systems approach to cognitive mapping. J Manage Inf Syst 11:31-57

Simons T, Pelled LH, Smith KA (1999) Making use of difference: diversity, debate, and decision comprehensiveness in top management teams. Acad Manage J 42:662-673. doi:10.2307/256987

Susman G, Evered R (1978) An assessment of the scientific merits of action research. Adm Sci Q 23:582603. doi: $10.2307 / 2392581$

Tegarden DP, Sheetz SD (2003) Group cognitive mapping: a methodology and system for capturing and evaluating managerial and organizational cognition. Omega 31:113-125. doi:10.1016/ S0305-0483(03)00018-5 
Valacich J, Vogel D, Nunamaker J (1992) Group size and anonymity effects on computer mediated idea generation. Small Group Res 23:49-73. doi:10.1177/1046496492231004

van den Herik CW, de Vreede GJ (2000) Experiences with facilitating policy meetings with group support systems. Int J Technol Manage 19:246-268. doi:10.1504/IJTM.2000.002819

Walsh JP (1995) Managerial and organizational cognition: notes from a trip down memory lane. Organ Sci 6:280-321

Weick KE, Roberts KH (1993) Collective mind in organizations: heedful interrelating on flight decks. Adm Sci Q 38:357-381. doi:10.2307/2393372

Winnicott DW (1953) Transitional objects and transitional phenomena: a study of the first not-me possession. Int J Psychoanal XXXIV(Part 2):89-97

Wright RP (2006) Rigor and relevance using repertory grid technique in strategy research. Res Methodol Strategy Manage 3:295-348 